\title{
Mouthguard Thermoforming Method to Decrease Palatal Thickness While Maintaining Labial and Buccal Thickness
}

\author{
Mutsumi Takahashi ${ }^{*}$, Yogetsu Bando² \\ ${ }^{1}$ Department of Physiology, The Nippon Dental University School of Life Dentistry at Niigata, Niigata, Japan \\ ${ }^{2}$ BANDO Dental Clinic, Ishikawa, Japan \\ Email: *mutsumit@ngt.ndu.ac.jp
}

How to cite this paper: Takahashi, M. and Bando, Y. (2020) Mouthguard Thermoforming Method to Decrease Palatal Thickness While Maintaining Labial and Buccal Thickness. Materials Sciences and Applications, 11, 370-381.

https://doi.org/10.4236/msa.2020.116025

Received: May 15, 2020

Accepted: June 15, 2020

Published: June 18, 2020

Copyright $\odot 2020$ by author(s) and Scientific Research Publishing Inc. This work is licensed under the Creative Commons Attribution International License (CC BY 4.0).

http://creativecommons.org/licenses/by/4.0/

\begin{abstract}
Wearing a mouthguard reduces the risk of sports-related injuries, but a more comfortable design is required in order to increase the wearing rate. The aim of this study was to investigate a thermoforming method that decreases palatal thickness while maintaining labial and buccal thickness. Mouthguards were fabricated from an ethylene-vinyl acetate sheet (thickness: $4.0 \mathrm{~mm}$ ) by using a vacuum forming machine. Four working models were prepared: 1 ) the anterior height was $25-\mathrm{mm}$ and the posterior height was $20-\mathrm{mm}$ (model A), 2) model A with the palate trimmed (model B), 3) heights $5 \mathrm{~mm}$ greater than model $\mathrm{A}$ (model C), and 4) model C with the palate trimmed (model D). The two forming conditions were as follows: 1) The sheet was formed when it sagged $15 \mathrm{~mm}$ below the level of the sheet frame at the top of the post under ordinary use (control); 2) The sheet frame at the top of the post was lowered and the sheet covered the model when it sagged by $15 \mathrm{~mm}$. The rear side of the model was pushed to move the model forward $20 \mathrm{~mm}$, and then the sheet was formed (MP). Differences in mouthguard thickness due to forming conditions and model forms were analyzed by two-way analysis of variance and Bonferroni's multiple comparison tests. Difference in forming conditions was similar for all model forms; for the MP, the thickness of the incisal edge, labial surface, cusp and buccal surface were greater, and the palatal surface was thinner than the control. On the labial and buccal surface, the thickness difference due to the model form was observed only for the MP, and models A and B were thicker than models $\mathrm{C}$ and $\mathrm{D}$. The palatal thickness tended to be thin in the models with the trimmed palate. This study suggested that the labial and buccal thickness of the mouthguard can be maintained, and the palatal thickness can be decreased by using the model with the palate trimmed with the forming method in which the model position is moved forward immediately before the vacuum formation.
\end{abstract}




\section{Keywords}

Mouthguard, Thermoforming, Thickness, Model Trimming, Moving Model Position

\section{Introduction}

Wearing a mouthguard decreases the risk of sports-related injuries, and the material and thickness of mouthguards have substantial effects on effectiveness and safety [1] [2] [3] [4] [5]. Custom-made mouthguards are very comfortable and safe compared with commercial products [4] [6]. Flasking and injection molding are superb techniques for producing mouthguards with appropriate thickness. In particular, injection molding is a practical technique that produces mouthguards that are very comfortable and provide excellent protection [6]. Thermoforming has the advantage of having a production process that is simple with a short turn-around time. Forming machines are now available with semi-automatic functions, heating time or temperature programs according to sheet thickness, and a device capable of making indentations of the occlusal surface [7] [8] [9]. These developments have made thermoforming mouthguard fabrication even easier.

It is crucial to provide a thickness of $3-4 \mathrm{~mm}$ on the labial and buccal sides of the mouthguard to ensure the proper distribution of force and counter the stress and strain generated during impact [10] [11] [12] [13]. However, a 35\% - 60\% decrease in post-formation thickness during thermoforming is large, so it is difficult to obtain sufficient thickness with a single layer [14] [15] [16] [17] [18]. To address this, several thermoforming methods have been investigated, such as controlling the heating temperature of the sheet or the sheet shape [19] [20] [21] [22] [23]. These methods can provide athletes with a thicker single-layer mouthguard than conventional methods. However, few reports have examined the palatal thickness of the mouthguard, even though it affects the tongue space [24] [25].

It is important to avoid a situation in which athletes refuse to wear mouthguards because of discomfort [24], thereby decreasing the incidence of sports-related orofacial damage. However, comfort and fit are the main reasons behind the low rate of athletes wearing mouthguards [26] [27] [28]. In a study of elite water polo players, decreasing the length of the palatal margin of the mouthguard decreased interference with basic oral functions, such as conversation, swallowing, and respiration, and increased overall satisfaction [24]. Decreasing the palatal margin was also confirmed to not affect tooth deflection, mouthguard retention, or protection ability [24] [29] [30] [31]. This indicates that the external form of the mouthguard improves player satisfaction. The improved comfort during speaking, breathing, and swallowing was explained by the greater space allowed for the tongue [24]. Thus, the comfort of mouthguards is affected by their external form and thickness.

The aim of this study was to investigate a method for fabricating mouthguards of sufficient thickness and comfort that resist external forces. That is, the mouth- 
guard thermoforming technique was examined that decreases palatal thickness while maintaining labial and buccal thickness.

\section{Materials and Methods}

Mouthguards were fabricated from an ethylene-vinyl acetate sheet (Sports Mouthguard, Keystone Dental Inc., Cherry Hill, NJ; $127 \times 127 \times 4.0 \mathrm{~mm}$, clear). A working model was fabricated using a silicone rubber (Correcsil, Yamahachi Dental Mfg. Co., Gamagori, Japan) impression taken from a maxillary dental model (D16FE-500A-QF, Nissin Dental Products Inc., Kyoto, Japan), into which dental gypsum (New Plastone, GC Co., Tokyo, Japan) was poured [15] [17] [23] [32] [33]. The gypsum model was trimmed using a model trimmer (MT-6, Morita Co., Tokyo, Japan), and a center trimmer (No. 528, Dentpia Co., Nagoya, Japan). Four working models were prepared: 1) $25-\mathrm{mm}$ high at the incisal edge of the maxillary central incisor and 20-mm high at the mesiobuccal cusp of the maxillary first molar (model A); 2) model A with the palate trimmed (model B); 3) $30-\mathrm{mm}$ high at the incisal edge of the maxillary central incisor and 25- $\mathrm{mm}$ high at the mesiobuccal cusp of the maxillary first molar (model C); and 4) model C with the palate trimmed (model D) (Figure 1). The trimmed palate of models B and $\mathrm{D}$ was adjusted so that the width of the model was $13 \mathrm{~mm}$ at the center of the central incisor and $18 \mathrm{~mm}$ at the first molar. All models were thoroughly dried for more than $48 \mathrm{~h}$ in an air-conditioned room before use.

Mouthguards were thermoformed using a vacuum forming machine (Pro-form, T\&S Dental \& Plastics Co., Inc., Myerstown, PA). The model was positioned 40 $\mathrm{mm}$ from the front of the forming unit. The sheet was softened until it sagged 15 $\mathrm{mm}$, after which the sheet frame was lowered to cover the model [7] [17] [33] [34]. The two forming conditions were as follows: 1) The sheet was formed when it sagged $15 \mathrm{~mm}$ below the level of the sheet frame at the top of the post under ordinary use (control) [7] [33] [34]; 2) The sheet frame at the top of the post was lowered and the sheet covered the model when it sagged by $15 \mathrm{~mm}$. The rear side of the model was pushed to move the model forward $20 \mathrm{~mm}$, and then the sheet was formed (MP) (Figure 2) [25] [33] [34]. Vacuum time was $30 \mathrm{~s}$ under both forming conditions. The model was left in place for $24 \mathrm{~h}$ or longer before the mouthguard was removed. Six specimens were formed for each condition. A total of 48 mouthguards were fabricated (i.e., 2 forming methods $\times 4$ model forms $\times 6$ repetitions).

After formation, the mouthguard thickness was determined using a specialized caliper accurate to $0.1 \mathrm{~mm}$ (21-111, YDM Co., Tokyo, Japan) without a spring, so as to prevent distortion during measurement [25] [32] [33] [34]. Following the methods of previous studies, the thickness of each specimen was measured at 5 points on the incisal edge, 10 points on the labial surface, 10 points on the anterior palate, 4 points on the cusp, and 10 points on the buccal surface. Ten points on the palatal side of the first molar (molar palate) were also measured (Figure 3) [25] [32] [33] [34]. The measurements were taken once for each specimen. 

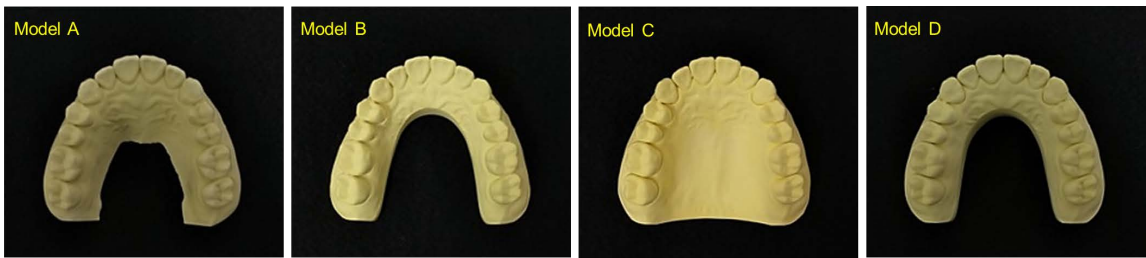

Figure 1. Working model. Model A, 25-mm high at the incisal edge of the maxillary central incisor and 20-mm high at the mesiobuccal cusp of the maxillary first molar; model B, palate trimmed and same height as model A; model C, 5-mm higher than model A; model $\mathrm{D}$, palate trimmed and same height as model C.
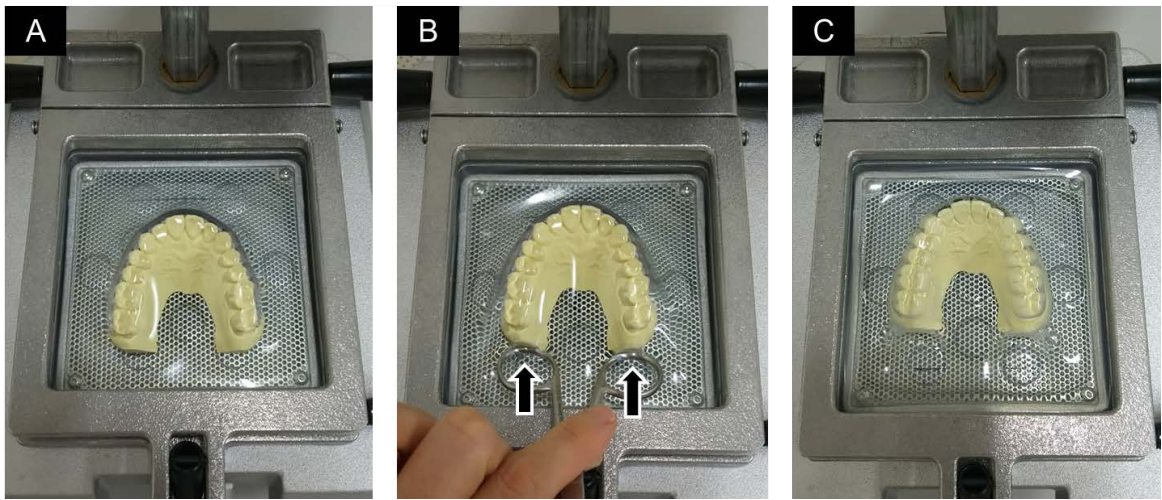

Figure 2. The MP method. (A), the sheet frame at the top of the post was lowered and the sheet covered the model when the sheet sagged by $15 \mathrm{~mm}$; (B), the rear side of the model was pushed forward $20 \mathrm{~mm}$; (C), the vacuum switch was turned on to form the sheet.
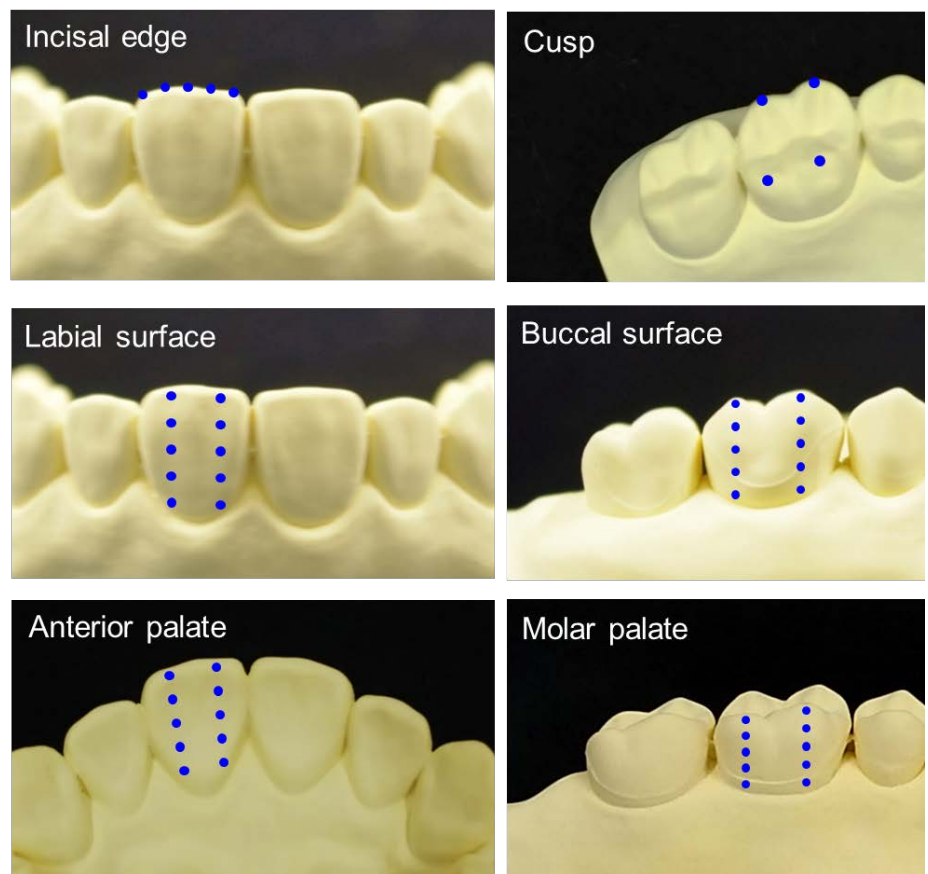

Figure 3. Measurement points for mouthguard thickness corresponding to the model. The anterior portion was defined as five points on the incisal edge and 10 points each on the labial and palatal surface at the left and right central incisors. The posterior portion was defined as four points on the cusp and 10 points each on the buccal and palatal surface at the left and right first molars. 
For all measurements, the differences in mouthguard thickness due to forming conditions and model forms were analyzed using statistical analysis software (IBM SPSS 24.0 SPSS Japan Inc., Tokyo, Japan). The Shapiro-Wilk test for normality of distribution and Levene's test for homogeneity of variance were also used. Each measurement exhibited normality and equal dispersion; accordingly, analysis was performed by two-way analysis of variance and Bonferroni's multiple comparison tests. All analytical methods were carried out with a significance level of $5 \%$ and a detection power of $80 \%$, and a difference was considered significant when both were satisfied.

\section{Results and Discussion}

Table 1 shows the results of two-way analysis of variance for the thickness of the mouthguard after formation. At all measurement points, the main effects of the forming condition and model form were significant, and their interaction was also significant. Based on the results, simple main effect tests were performed prior to multiple comparisons among levels.

Figures $4(\mathrm{~A})$-(F) and Table 2 show the results of multiple comparison analysis. The difference in forming conditions was similar for all model forms; the thickness of the incisal edge, labial surface, cusp and buccal surface were greater for the MP conditions and the palatal surface was thinner for the MP condition than the control condition. On the labial and buccal surface, the difference in the thickness due to the model form was observed only for MP condition, and the thicknesses were greater for models $\mathrm{A}$ and $\mathrm{B}$ than for models $\mathrm{C}$ and $\mathrm{D}$. The palatal thickness of the mouthguard tended to be thin in the models with the trimmed palate.

The results of this study suggest that the labial and buccal thickness can be made thicker and the palatal thickness thinner than with the conventional method by adjusting the forming method and model form during thermoforming. The MP condition ensures the labial thickness is approximately 1.5 times that of the conventional method [34]. In addition, the palatal thickness decreases because the sheet elongated by the model movement is formed against the palate side of the model [25]. In this study, the model form was focused to improve the method for maintaining the labial and buccal thickness and reducing the palatal thickness under the MP condition. In the working model form, high height and sharp edges of the model make the sheet thinner during thermoforming, whereas the short and smooth surfaces are less likely to make the sheet thinner [15] [33]. Trimming the palate was examined as one of the improvements to the model form without affecting the external shape of the mouthguard and without complication. Palate trimming creates a step or corner at the border between the impression surface and the trimming surface, increasing the surface area against which the softened sheet is pressed. It was expected that this form would elongate the sheet during formation. Model A was a form with a decreased height that included a sufficient impression area to form the mouthguard. However, part of 
the palate areas were removed by decreasing the height, and thus it was difficult to determine the effect of trimming the palate. Therefore, model $\mathrm{C}$ was prepared, in which the palate was completely present.

Table 1. Results of two-way analysis of variance for thickness after formation.

\begin{tabular}{llllll}
\hline Source & $d f$ & SS & MS & $F$-value & $P$-value \\
\hline Incisal edge & & & & & \\
Forming condition (A) & 1 & 1.425 & 1.425 & 3846.620 & $<0.001^{\star *}$ \\
Model form (B) & 3 & 0.072 & 0.024 & 64.693 & $<0.001^{* *}$ \\
$\mathrm{~A}^{\star B}$ & 3 & 0.005 & 0.002 & 4.580 & $<0.01^{\star *}$ \\
Error & 40 & 0.015 & 0.000 &
\end{tabular}

Labial surface

$\begin{array}{llllll}\text { Forming condition (A) } & 1 & 12.536 & 12.536 & 37,006.205 & <0.001^{\star *} \\ \text { Model form (B) } & 3 & 0.886 & 0.295 & 872.200 & <0.001^{\star *} \\ \mathrm{~A}^{\star} \mathrm{B} & 3 & 0.325 & 0.108 & 319.826 & <0.001^{\star *} \\ \text { Error } & 40 & 0.014 & 0.000 & \end{array}$

Anterior palate

$\begin{array}{llllll}\text { Forming condition (A) } & 1 & 0.949 & 0.949 & 1922.468 & <0.001^{* *} \\ \text { Model form (B) } & 3 & 0.866 & 0.286 & 28.771 & <0.001^{* *} \\ \mathrm{~A}^{\star} \mathrm{B} & 3 & 0.018 & 0.006 & 60.469 & <0.001^{\star *} \\ \text { Error } & 40 & 0.020 & 0.000 & \end{array}$

Cusp

Forming condition (A)

Model form (B)

$\mathrm{A}^{* \mathrm{~B}}$

2.637

2.637

4373.272

$<0.001^{\star *}$

Error

0.052

0.017

28.771

$<0.001^{* *}$

0.109

0.036

60.469

$<0.001^{* *}$

Buccal surface

Forming condition (A)

Model form (B)

2.544

2.544

6628.800

$<0.001^{* *}$

$A^{\star B}$

0.616

0.205

535.293

$<0.001^{\star *}$

Error

3

0.293

0.098

254.627

$<0.001^{* *}$

Molar palate

$\begin{array}{llllll}\text { Forming condition (A) } & 1 & 0.317 & 0.317 & 592.290 & <0.001^{* *} \\ \text { Model form (B) } & 3 & 0.216 & 0.072 & 134.798 & <0.001^{\star *} \\ \mathrm{~A}^{\star} \mathrm{B} & 3 & 0.052 & 0.017 & 32.674 & <0.001^{* *} \\ \text { Error } & 40 & 0.021 & 0.001 & & \end{array}$

$d f$ degree of freedom. SS: sum of squares. MS: mean square. ${ }^{* *} P<0.01$ : denotes statistically significant difference. 
Table 2. Results of Bonferroni's multiple comparison tests according to the model form.

\begin{tabular}{|c|c|c|c|c|c|c|c|}
\hline \multicolumn{4}{|c|}{ Incisal edge } & \multicolumn{4}{|c|}{ Cusp } \\
\hline Control & Model A & Model B & Model C Model D & Control & Model A & Model B & Model C Model D \\
\hline Model A & & & & Model A & & & \\
\hline Model B & n.s. & & & Model B & n.s. & & \\
\hline Model C & n.s. & n.s. & & Model C & n.s. & n.s. & \\
\hline Model D & n.s. & n.s. & n.s. & Model D & n.s. & n.s. & n.s. \\
\hline MP & Model A & Model B & Model C Model D & MP & Model A & Model B & Model C Model D \\
\hline Model A & & & & Model A & & & \\
\hline Model B & n.s. & & & Model B & n.s. & & \\
\hline Model C & n.s. & n.s. & & Model C & n.s. & n.s. & \\
\hline Model D & n.s. & n.s. & n.s. & Model D & n.s. & n.s. & n.s. \\
\hline & n.s.: 1 & not signific & icant. & & n.s.: & not signifi & icant. \\
\hline & & abial surfac & & & & uccal surfa & \\
\hline Control & Model A & Model B & Model C Model D & Control & Model A & Model B & Model C Model D \\
\hline Model A & & & & Model A & & & \\
\hline Model B & n.s. & & & Model B & n.s. & & \\
\hline Model C & n.s. & n.s. & & Model C & n.s. & n.s. & \\
\hline Model D & n.s. & n.s. & n.s. & Model D & n.s. & n.s. & n.s. \\
\hline MP & Model A & Model B & Model C Model D & MP & Model A & Model B & Model C Model D \\
\hline Model A & & & & Model A & & & \\
\hline Model B & n.s. & & & Model B & n.s. & & \\
\hline Model C & $* *$ & ** & & Model C & $* *$ & $* *$ & \\
\hline Model D & $* *$ & $* *$ & n.s. & Model D & $* *$ & $* *$ & n.s. \\
\hline & ${ }^{* *} P<0.01$ & ; n.s.: not si & significant. & & ${ }^{*} P<0.01$ & ; n.s.: not & significant. \\
\hline & & nterior pala & & & & Molar pala & \\
\hline Control & Model A & Model B & Model C Model D & Control & Model A & Model B & Model C Model D \\
\hline Model A & & & & Model A & & & \\
\hline Model B & n.s. & & & Model B & n.s. & & \\
\hline Model C & $* *$ & $* *$ & & Model C & n.s. & $* *$ & \\
\hline Model D & n.s. & n.s. & $* *$ & Model D & $* *$ & n.s. & $* *$ \\
\hline MP & Model A & Model B & Model C Model D & MP & Model A & Model B & Model C Model D \\
\hline Model A & & & & Model A & & & \\
\hline Model B & n.s. & & & Model B & n.s. & & \\
\hline Model C & n.s. & ** & & Model C & n.s. & n.s. & \\
\hline Model D & $* *$ & n.s. & $* *$ & Model D & $* *$ & n.s. & n.s. \\
\hline & ${ }^{* *} P<0.01$ & ; n.s.: not si & significant. & & ${ }^{* *} P<0.01$ & ; n.s.: not s & significant. \\
\hline
\end{tabular}


A

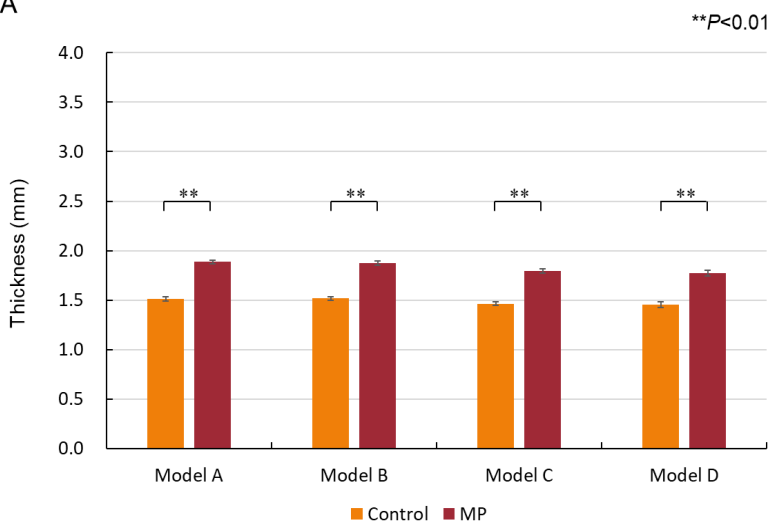

B

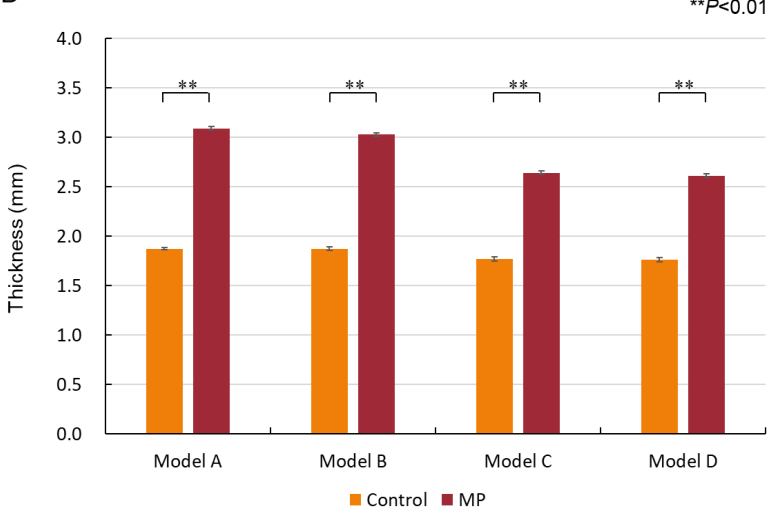

C

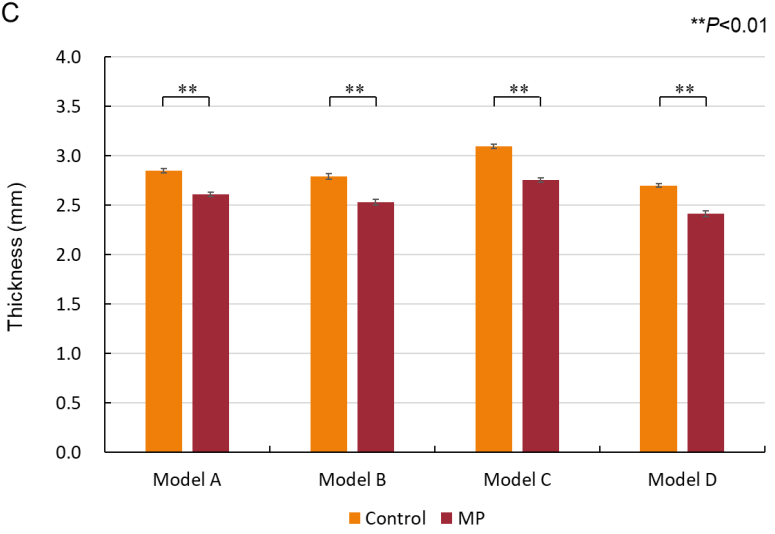

D

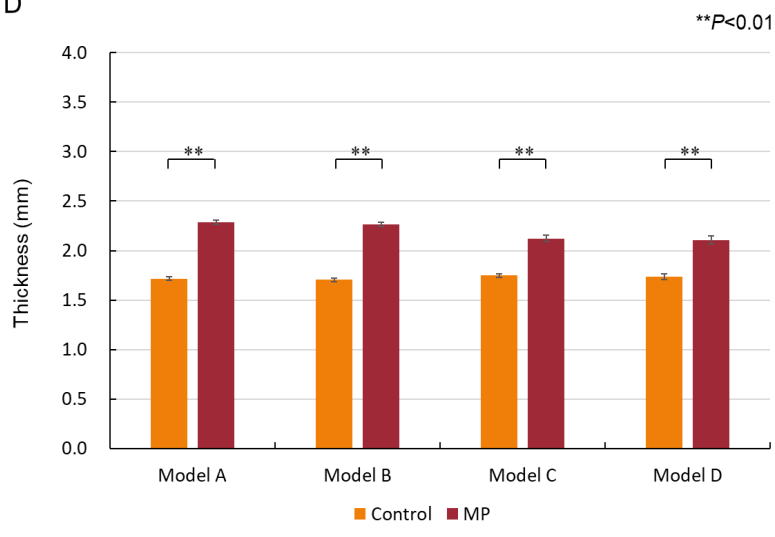

E

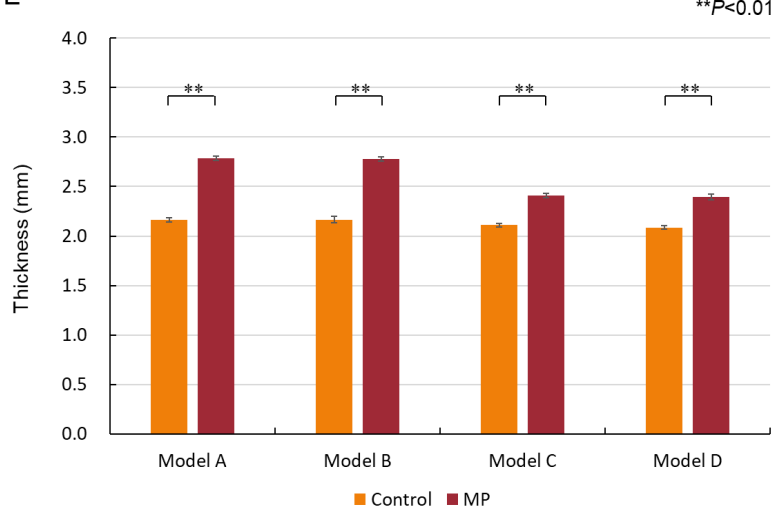

$\mathrm{F}$

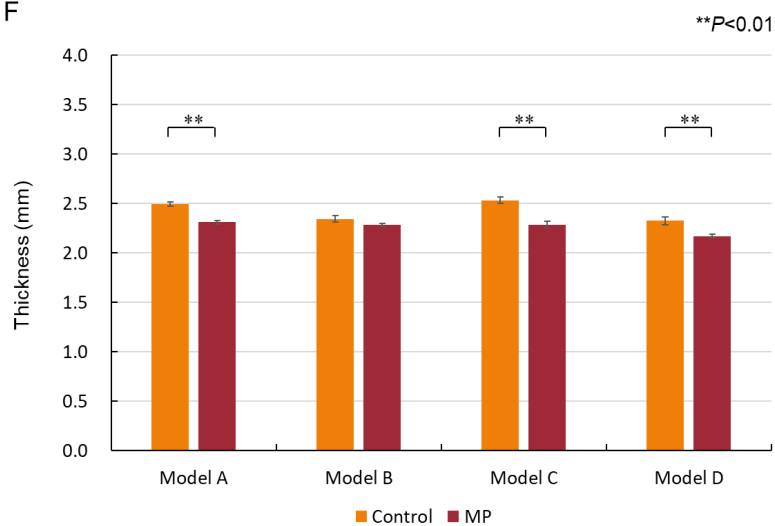

Figure 4. Multiple comparison analysis of the mouthguard thicknesses formed under control and model position (MP) conditions at the (A) incisal edge, (B) labial surface, (C) anterior palate, (D) cusp, (E) buccal surface, and (F) molar palate.

The MP conditions gave thicker mouthguards, except for the anterior palate and the posterior palate, and showed the same trends as reported previously [25]. This study was examined whether palatal trimming and MP conditions do not affect the labial and buccal thickness and lead to a thinner palatal side. First, it was determined that the effectiveness of palatal trimming by comparing models $\mathrm{C}$ and $\mathrm{D}$. Second, it was considered whether the difference between models $\mathrm{C}$ and D was similar to the difference between models A and B. Third, it was investigated 
whether it was more effective to trim the palate, even if the height of the model was increased.

There was no significant difference in thickness between models $C$ and $D$, other than in the palate under both forming conditions. The anterior palate was thinner for model D than for model C. The palate for model C had a smooth impression surface, whereas for model $\mathrm{D}$, the sheet was pressed into a corner formed by the impression surface and the trimmed surface. The effect of the model form on the thickness of the molar palate was less than that on the thickness of the anterior palate. The height of the molars was lower and they had fewer edges than the anterior part, and there was less morphological difference was caused by palatal trimming.

There was no significant difference between models A and B at any of the measurement points under both forming conditions. The palatal thickness tended to be thinner in model B than in model A, but the difference was smaller than that between models $\mathrm{C}$ and $\mathrm{D}$. These two comparisons showed that for athletes with a deep palate, palate trimming of the model does not significantly affect the mouthguard thickness, whereas for athletes with a shallow palate, it makes the mouthguard palatal side thinner.

Under the MP conditions, there was no significant difference between models $\mathrm{B}$ and $\mathrm{D}$ in the thickness of the anterior and molar palates. The height of the model with the palate trimmed did not affect the palatal thickness of the mouthguard. However, the labial and buccal thickness were affected by the model height, and model D was thinner than model B. Under the MP conditions, model D was thinner than model A on the palate side, and on the labial and buccal sides. Therefore, the hypothesis that it would be more effective to increase the height of the model and trim the palate side did not hold. However, trimming the palate would not adversely affect the absorption and dispersion of impact forces because there was no significant difference in thickness except for the palate side between models $\mathrm{A}$ and $\mathrm{B}$, or between models $\mathrm{C}$ and $\mathrm{D}$.

\section{Conclusion}

This study suggested that the labial and buccal thickness of the mouthguard can be maintained, and the palatal thickness can be decreased by using the model with the palate trimmed with the forming method in which the model position is moved forward immediately before the vacuum formation. This method is expected to contribute to improving athletes' comfort when wearing a mouthguard.

\section{Funding}

This study was supported by Nippon Dental University Intramural Research Fund.

\section{Conflicts of Interest}

The authors declare no conflicts of interest regarding the publication of this paper. 


\section{References}

[1] Verissimo, C., Costa, P.V., Santos-Filho, P.C., Tantbirojn, D., Versluis, A. and Soares, C.J. (2016) Custom-Fitted EVA Mouthguards: What Is the Ideal Thickness? A Dynamic Finite Element Impact Study. Dental Traumatology, 32, 95-102. https://doi.org/10.1111/edt.12210

[2] Gialain, I.O., Coto, N.P., Driemeier, L., Noritomi, P.Y. and Dias, R.B. (2016) A Three-Dimensional Finite Element Analysis of the Sports Mouthguard. Dental Traumatology, 32, 409-415. https://doi.org/10.1111/edt.12265

[3] Bochnig, M.S., Oh, M.J., Nagel, T., Ziegler, F. and Jost-Brinkmann, P.G. (2017) Comparison of the Shock Absorption Capacities of Different Mouthguards. Dental Traumatology, 33, 205-213. https://doi.org/10.1111/edt.12324

[4] Gawlak, D., Mańka-Malara, K., Mierzwińska-Nastalska, E., Gieleta, R., Kamiński, T. and Łuniewska, M. (2017) A Comparison of Impact Force Reduction by Polymer Materials Used for Mouthguard Fabrication. Acta Bioeng Biomech, 19, 89-95.

[5] Tribst, J.P.M., de Oliveira Dal Piva, A.M., Borges, A.L.S. and Bottino, M.A. (2018) Influence of Custom-Made and Stock Mouthguard Thickness on Biomechanical Response to a Simulated Impact. Dental Traumatology, 34, 429-437.

https://doi.org/10.1111/edt.12432

[6] Gawlak, D., Mierzwińska-Nastalska, E., Mańka-Malara, K. and Kamiński, T. (2015) Assessment of Custom and Standard, Self-Adapted Mouthguards in Terms of Comfort and Users Subjective Impressions of Their Protective Function. Dental Traumatology, 31, 113-117. https://doi.org/10.1111/edt.12132

[7] Takeuchi, M. and Togaya, N. (2006) Effectively of Thermoforming Process for Fabricating of Intraoral Apparatus. Sunashobo, Tokyo, 21-26, 33-44, 54-55, 62-67, 81. (In Japanese)

[8] Erkodent Dental Products. ERKODENT ${ }^{\circ}$ Thermoforming Systems. https://glidewelldirect.com/collections/erkodent

[9] Dreve Dentamid. Thermoforming Technique. https://dentamidshop.dreve.de/dentamiden/catalog/category/view/s/thermoformin g-technique/id/110/?p=2

[10] Bemelmanns, P. and Pfeiffer, P. (2001) Shock Absorption Capacities of Mouthguards in Different Types and Thicknesses. International Journal of Sports Medicine, 22, 149-153. https://doi.org/10.1055/s-2001-11342

[11] Westerman, B., Stringfellow, P.M. and Eccleston, J.A. (2002) EVA Mouthguards: How Thick Should They Be? Dental Traumatology, 18, 24-27. https://doi.org/10.1034/j.1600-9657.2002.180103.x

[12] Geary, J.L. and Kinirons, M.J. (2008) Post Thermoforming Dimensional Changes of Ethylene Vinyl Acetate Used in Custom-Made Mouthguards for Trauma Prevention: A Pilot Study. Dental Traumatology, 24, 350-355. https://doi.org/10.1111/j.1600-9657.2007.00550.x

[13] Maeda, M., Takeda, T., Nakajima, K., Shibusawa, M., Kurokawa, K., Shimada, A., et al. (2008) In Search of Necessary Mouthguard Thickness: Part 1 from the View Point of Shock Absorption Ability. The Journal of Japan Prosthodontic Society, 52, 211-219.

[14] Del Rossi, G. and Leyte-Vidal, M.A. (2007) Fabricating a Better Mouthguard: Part I Factors Influencing Mouthguard Thinning. Dental Traumatology, 23, 149-154. https://doi.org/10.1111/j.1600-9657.2006.00436.x

[15] Takahashi, M., Koide, K., Satoh, Y. and Iwasaki, S. (2016) Shape Change in Mouthguard Sheets during Thermoforming. Dental Traumatology, 32, 379-384. https://doi.org/10.1111/edt.12261 
[16] Farrington, T., Coward, T., Onambele-Pearson, G., Taylor, R.L., Earl, P. and Winwood, K. (2016) An Investigation into the Relationship between Thickness Variations and Manufacturing Techniques of Mouthguards. Dental Traumatology, 32, 14-21. https://doi.org/10.1111/edt.12192

[17] Takahashi, M., Araie, Y., Satoh, Y. and Iwasaki, S. (2017) Shape Change in Mouthguard Sheets during Thermoforming: Part 2 Effect of the Anteroposterior Position of the Model on Fabricated Mouthguard Thickness. Dental Traumatology, 33, 114-120. https://doi.org/10.1111/edt.12319

[18] Parker, K., Marlow, B., Patel, N. and Gill, D.S. (2017) A Review of Mouthguards: Effectiveness, Types, Characteristics and Indications for Use. British Dental Journal, 222, 629-633. https://doi.org/10.1038/sj.bdj.2017.365

[19] Mizuhashi, F., Koide, K., Takahashi, M. and Mizuhashi, R. (2012) A Method to Maintain the Thickness of the Mouthguard after the Vacuum Forming Process: Changes of the Holding Conditions of the Mouthguard Sheet. Dental Traumatology, 28, 291-295. https://doi.org/10.1111/j.1600-9657.2011.01091.x

[20] Takahashi, M., Koide, K. and Mizuhashi, F. (2012) Difference in the Thickness of Mouthguards Fabricated from Step-Type Polyolefin-Polystyrene Copolymer Sheets Differently Arranged v-Shaped Grooves. Journal of Prosthodontic Research, 56, 281-286. https://doi.org/10.1016/j.jpor.2012.03.001

[21] Takahashi, M., Koide, K. and Mizuhashi, F. (2015) Variation in Mouthguard Thickness Due to Different Heating Conditions during Fabrication: Part 2. Dental Traumatology, 31, 18-23. https://doi.org/10.1111/edt.12122

[22] Takahashi, M. and Koide, K. (2016) Variation in Mouthguard Thickness According to Heating Conditions during Fabrication: Part 2 Sheet Shape and Effect of Thermal Shrinkage. Dental Traumatology, 32, 185-191. https://doi.org/10.1111/edt.12209

[23] Takahashi, M., Koide, K., Satoh, Y. and Iwasaki, S. (2016) Heating Methods for Reducing Unevenness Softening of Mouthguard Sheets in Vacuum-Pressure Formation. Dental Traumatology, 32, 316-320. https://doi.org/10.1111/edt.12254

[24] Gómez-Gimeno, À., Zamora-Olave, C., Cordobés-Navarro, M., Willaert, E. and Martinez-Gomis, J. (2019) Satisfaction with Shortening the Palatal Extension of a Mouthguard for Water Polo Players: A Randomized Crossover Study. Dental Traumatology, 35, 135-141. https://doi.org/10.1111/edt.12455

[25] Takahashi, M. and Bando, Y. (2019) Thermoforming Technique for Maintaining the Thickness of Single-Layer Mouthguard during Pressure Formation. Dental Traumatology, 35, 285-290. https://doi.org/10.1111/edt.12472

[26] Ilia, E., Metcalfe, K. and Heffernan, M. (2014) Prevalence of Dental Trauma and Use of Mouthguards in Rugby Union Players. Australian Dental Journal, 59, 473-481. https://doi.org/10.1111/adj.12223

[27] Bergman, L., Milardović, Ortolan. S., Žarković, D., Viskić, J., Jokić, D. and Mehulić, K. (2017) Prevalence of Dental Trauma and Use of Mouthguards in Professional Handball Players. Dental Traumatology, 33, 199-204. https://doi.org/10.1111/edt.12323

[28] Afrashtehfar, K.I. and Chung, J. (2017) Mouthguard Use May Reduce Dentofacial Injuries in Field Hockey Players. Evidence-Based Dentistry, 18, 48-49. https://doi.org/10.1038/sj.ebd.6401239

[29] Yamada, J., Maeda, Y., Satoh, H. and Miura, J. (2006) Anterior Palatal Mouthguard Margin Location and Its Effect on Shock-Absorbing Capability. Dental Traumatology, 22, 139-144. https://doi.org/10.1111/j.1600-9657.2006.00393.x 
[30] Maeda, Y., Machi, H. and Tsugawa, T. (2006) Influences of Palatal Side Design and Finishing on the Wearability and Retention of Mouthguards. British Journal of Sports Medicine, 40, 1006-1008. https://doi.org/10.1136/bjsm.2006.030874

[31] Gebauer, D.P., Williamson, R.A., Wallman, K.E. and Dawson, B.T. (2011) The Effect of Mouthguard Design on Respiratory Function in Athletes. Clinical Journal of Sport Medicine, 21, 95-100. https://doi.org/10.1097/JSM.0b013e31820428b0

[32] Takahashi, M. and Bando, Y. (2018) Effect of the Anteroposterior Position of the Model on Fabricated Mouthguard Thickness: Part 2 Influence of Sheet Thickness and Material. Dental Traumatology, 34, 370-377. https://doi.org/10.1111/edt.12423

[33] Takahashi, M. and Bando, Y. (2019) Thermoforming Method to Effectively Maintain Mouthguard Thickness: Effect of Moving the Model Position Just before Vacuum Formation. Dental Traumatology, 35, 121-127.

https://doi.org/10.1111/edt.12447

[34] Takahashi, M. and Bando, Y. (2019) Movement of Model Position Just before Vacuum Forming to Ensure Mouthguard Thickness: Part 2 Effect of Model Moving Distance. Dental Traumatology, 35, 291-295. https://doi.org/10.1111/edt.12499 